\title{
Adoption of E-learning System in Higher Education Environments: Evidence from Modified UTAUT Model
}

\author{
Wasim Qazi ${ }^{2}$, Syed Ali Raza1 ${ }^{*}$, Komal Akram Khan'1, and Javeria Salam¹ \\ ${ }^{1}$ Department of Business Administration, IQRA University Karachi-75300, Pakistan \\ 2Department of Education and Learning Sciences, IQRA University Karachi-75300, \\ Pakistan \\ *Corresponding author E-mail :syed_aliraza@hotmail.com \\ https://doi.org/10.12982/CMUJASR.2020.003
}

\section{ABSTRACT}

E-Learning has been an exceptional support for learners across the globe. Many people are using electronic media for different purposes. Hence, learners, especially students, can benefit from the electronic system as well. Therefore, the purpose of this study is to examine the adoption level of e-learning systems by using the extended model of UTAUT2. The data was collected using the survey method, and for this purpose, the five-point Likert scale has been used. The statistical techniques applied to the data set were confirmatory factor analysis and partial least square structural equation modeling. The results reveal that performance expectancy, effort expectancy, social influence, facilitating conditions, habit, knowledge acquisition, and knowledge sharing are positively linked with behavioral intention to use e-learning systems except for hedonic motivation. The modified model adds two new predictors: knowledge acquisition and knowledge sharing that influence students' acceptance of e-learning systems. Therefore, it will provide the educationists and policymakers a new insight into whether students are willing to adopt the E-learning system for daily use.

Keywords: E-Learning System, Behavioral intention, Knowledge acquisition, Knowledge sharing, Higher education, PLS-SEM

\section{INTRODUCTION}

Many new applications have been developed because of the rapid evolution and advancement in the information technology sector including e-commerce, e-banking, and e-marketing. One prominent application is the e-learning system (ELS) (Alsabawy et al., 2016; Islam, 2016). The ELS is currently being widely recognized and used in the educational sector as an essential application that reduces time and location barriers, granting access to information quickly to people in pursuit of higher education (Althunibat, 2015; Al-Emran et al., 2020). ELS is now considered a strong resource in Western countries and other nations of the world as it expands the conventional learning model by building capacity in education and training through the use of information and communication technology (ICTs) (Alfraih \& Alanezi, 2016; Mikhaylov \& Fierro, 2015). 
Al-Busaidi (2012) claimed that ELS is not only for equipping institutions with efficient means to teach and train, but it also aims to share its knowledge and resources through efficient coding systems. Thus, it can be simply known as a process of delivering education through the use of computers and the internet, enabling students to access course materials to study online, offline, or a mix of the two modes (Al-Busaidi, 2013). Tarhini et al. (2017) stated that ELS provides students with a flexibility concerning location and time, making it an effective means of education that incorporates efficiency, communication, and self-motivation. Thus, this has made ELS an essential part of the educational process. The ELS is also an effective component of corporate training and workshops within organizations, enabling them to consistently train staff worldwide, reduce the delivery cycle and time, avoid information overload, and most importantly, reduce the training costs (Welsh et al., 2003).

According to Global Market Insights (2019), the ELS market worldwide is projected to be at US\$300bn by 2025. A common trend among higher educational institutions worldwide is the attempt to integrate ELS into their traditional learning curriculum where their delivery system can be improved and a blended learning environment can be created (Ugur \& Turan, 2018). This adds significant value to both the enrolled students (Villesseche et al., 2019) and to the institutions leading them to improve the quality of teaching (Zhang et al., 2020). Driscoll (2002) categorized the benefits of the ELS system into two where the first refers to the strategic benefits involving the overall improvement of the institution's competitive advantage, while the second is technical, which includes reducing expenditure and making better use of resources.

Some scholars also argued that skillful, committed, and engaged academicians and self-disciplined students play a crucial role in the successful implementation of ELS in educational institutions (Agrawal et al.,2016; Purbojo, 2018). This means that regardless of how useful ELS appears to be, the true advantages cannot be seen until the students use the technology efficiently. Thus, it ultimately reduces the effectiveness of the ELS (Tarhini et al., 2017). So, Alqirim et al. (2017) and Clay et al. (2008) stated that the success of ELS depends on the willingness of students to adopt the system. Further, one of the main challenges for the successful incorporation of ELS is the consistent high drop-out rates. Many learners find it impossible to finish the course on e-learning systems. Reducing dropout rates has become a crucial issue for the long-term success of e-learning (Zhou et al., 2020). Therefore, to enhance students' learning experience in ELS, it has become imperative for practitioners, policymakers, and researchers to discover factors that may improve or hinder students' willingness to adopt an ELS (Liaw \& Huang, 2011).

Tarhini et al. (2017) revealed that if institutions would want ELS to be successful, it is crucial for these institutions to explore the students' behavioral intentions (BI). Several scholars have used different theoretical models to explore BI with a specific technology, which includes the following: (a) the technology acceptance model (TAM) (Davis, 1989); (b) the theory of planned behavior (TPB) (Ajzen, 1991); (c) the theory of reasoned action (TRA) (Fishbein \& Ajzen, 1975); (d) the unified theory of acceptance and use of technology (UTAUT) (Vankatesh et al., 2003); and lastly, (e) the UTAUT2 (Venkatesh et al., 2012). Among these, the most 
popular model for assessing behavior intention by researchers today is UTAUT and its extended version, the UTAUT2. This model has been used to measure the BI of individuals who have used information technology in general (Venkatesh \& Bala, 2008; Vankatesh et al., 2003; Venkatesh et al., 2012). Several scholars have also used these models in the ELS context (Ain et al., 2016; El-Masri \& Tarhini, 2017; Teo, 2014; Zhang et al., 2008; Zwain 2019).

Even though significant research has been done in the area of online education in Pakistan, little attention has been paid to identify the factors that influence the adoption of ELS among Pakistani students. Additionally, in the recent pandemic, the education sector has completely transformed its teaching methodologies. So, it's high time to understand the situation of ELS in such states where ELS has been newly implemented. Especially in a country like Pakistan, it is crucial to examine students' BI towards adopting ELS because an unexpected shift from face-to-face interaction to online learning can cause various challenges to arise for both institutions and students.

In contrast, developed countries have been practicing online education for a long time. In such countries, teachers and students are familiar with E-learning; thus, the students' acceptance ratio of ELS is high. On the other hand, in developing countries, students are reluctant to adopt an online platform for learning purposes. Thus, by expanding the existing theory, we can evaluate whether students intend to use ELS. Another motivation behind conducting the research is to find out the prevailing scope of ELS in Pakistan. The concept of online education has taken a rise, and now many institutions are offering online courses, diplomas, and certifications. Also, millions of students in Pakistan pursue this new online-based curriculum and obtain a significant number of experiences while also acquiring certificates relevant to their professional lives (Shehzadi et al., 2020). Many educational websites serve this function by offering a wide variety of free classes and tutorials that can be completed at students' convenience. As a result, online learning in Pakistan is gaining attention. Students can choose careers that suit their interests and skills without worrying about budgets or age restrictions. This means that they can get an education in any area and at any time. As a result, ESL has promoted diversity in education. Due to the expansion of online education, more and more people are taking advantage of this technology. However, students from higher education still favor face-to-face classes because they prefer to continue their semesters on the campus (Anwar et al., 2020). In other words, while the online learning sector has been growing and experiencing a boom recently, students in universities crave for physical classes. So, the pertinent question arising out of this context is: "Are students ready to adopt ELS?" Hence, this paper is designed to study the factors that influence the adoption of ELS among Pakistani students.

The empirical review of the existing literature has revealed a gap in the understanding of the factors influencing students' BI in using ELS in Pakistan, which indicates an opportunity to explore ELS adoption factors locally. Therefore, this paper aims to examine the most crucial factors influencing students' BI to use ELS. Besides contributing to the extant literature, the findings of this research provide a detailed analysis of factors that influence ELS adoption in Pakistan, which facilitates the administrators, policymakers, and academicians to successfully implement ELS in higher educational institutes in Pakistan. Drawing from such a detailed analysis, 
the different aforementioned stakeholders will gain a deeper understanding of what needs to be developed and improved for a better incorporation of ELS. Furthermore, the results will prove to be useful for relevant decision-makers in making plans and setting policies for the adoption and design of ELS in the higher educational institutes. Essentially, this study will create a flourishing environment for the engagement of ELS in a developing country.

Following the introduction, this paper will highlight the literature review focusing on the theoretical foundation and hypotheses of this study. Next, the third section will present a discussion of the research methodology. Subsequently, the fourth section discusses the analysis of the collected data and the results obtained. Finally, this paper will conclude with a focus on the primary outcomes of this study. As a conclusion, this paper will provide the recommendations for theory and practice while revealing the research limitations and proposing possible directions for future research.

\section{LITERATURE REVIEW}

\section{Theoretical Background}

In the present study, UTAUT2 theory has been used to understand the students' behavioral intention to use ELS. This theory was developed by Venkatesh et al. (2012) to accurately analyze the variables for technology acceptance from customers' perspectives. However, the previous one, referring to the UTAUT model, evaluated employees' perspectives. The original UTAUT model was designed by assessing eight preceding theories that researched individual acceptance of the technology. Nonetheless, the review enabled the development of a unified model that was proven capable of viewing the complete picture of factors to understand technology acceptance (Al-Imarah et al., 2013). As a result, the newer model could predict 69 percent of the variance in BI to use innovative technology, while the previous model could only predict around 17 to 53 percent (Vankatesh et al., 2003).

In the current research, we have used the existing constructs of the UTAUT2 while excluding the price value. Further, the model has been extended by incorporating two knowledge management factors, which include knowledge acquisition (KA) and knowledge sharing (KS). According to Ali et al. (2018), these factors are the main determinants of technology adoption. Also, ELS is viewed as a potential tool for enabling KA and KS through ICTs (Al-Emran et al., 2020). So, it is believed that the added factors might play a dominant role in explaining BI to use ELS among students.

\section{Hypotheses Development}

\section{Behavioral Intention (BI) to use E-Learning System (ELS)}

According to Davis (1989), Behavioral Intention (BI) is an individual's readiness to adopt or accept the use of innovative technology. It can also be referred to as the subjective probability of an individual to perform a specific behavior (Zhang et al., 2020). In this paper, BI is concerned with the students' adoption of e-learning systems. Ajzen (2012) described it as the motivational factor showing how ready a person is to participate in the ELS. Furthermore, recent research by Altalhi (2021) claimed that a primary consideration in the use of technology is 
behavioral intention. The critical basis that measures the individual's actual actions in using technology lies in whether the individual has expressed the characteristic of behavioral intention. Thus, studying and examining students' BI to use ELS is critical as it will help in the promotion of the use of ELS significantly.

\section{Performance Expectancy (PE)}

The user's perception of how much a specific technology will enhance their performance in a specific activity is their Performance Expectancy (PE) (Venkatesh et al., 2012). According to Raza et al. (2021), PE is a students' belief regarding the use of ELS for enhancing learning performance. More precisely, it relates to an individual's educational performance, which a user aims to achieve by implementing ELS. Another research claimed that PE is the most powerful predictor of behavioral intentions to use Moodle. It stated that the main concern for students is to enhance their academic performance, and students believe that their academic performance can be improved by using the efficient technological tool, which is Moodle (Abbad, 2021). Furthermore, several studies found that PE is positively correlated with BI where different kinds of technologies, including the area of internet banking (Alalwan et al., 2014), e-government (Vinodh \& Mathew, 2012; Rana et al., 2013), and also in the ELS context (Ain et al., 2016; El-Masri \& Tarhini, 2017; Gunasinghe et al., 2019; Šumak et al., 2010; Šumak \& Šorgo, 2016; Tarhini et al., 2017; Teo \& Noyes, 2014) are used. Accordingly, the authors of this paper hypothesize the following statement:

H1: Performance Expectancy positively affects Behavioral Intention to use E-Learning System.

\section{Effort Expectancy (EE)}

An individual might perceive that the use of a specific technology is easy and hassle-free because of its Effort Expectancy (EE) (Vankatesh et al., 2003; Venkatesh et al., 2012). EE could be referred to as "the level of ease" associated with a program by rendering the use and implementation trouble-free (Yadav et al., 2016). Regarding the context of the study, EE is a student's belief in the level of ease of use associated with an ELS for course completion (Sidik \& Syafar, 2020). Hence, when students find ELS hassle-free and are satisfied with the learning process, they ultimately foster the intention to continue using Google Classroom (Al-Maroof \& Salloum, 2020). A recent study has revealed that EE is positively linked with BI to use innovative technology (Yadegaridehkordi et al., 2020; Zuiderwijk et al., 2015). Hence, it indicates that EE is an essential factor for determining students' BI to use ELS (Alalwan et al., 2015; Gruzd et al., 2012; Gunasinghe et al., 2019; Tarhini et al., 2017). Hence, the authors of this paper hypothesize the following statement:

H2: Effort Expectancy positively affects Behavioral Intention to use E-Learning System.

\section{Social Influence (SI)}

Venkatesh et al. (2012) described Social Influence (SI) as the extent of an individual's belief that society needs him to adopt a particular technology. Likewise, the people around him must believe that using relative technology is essential for him (Joa \& Magsamen-Conrad, 2021). Based on the context of this paper, SI refers to 
the external pressure on students exerted on them from peers, faculty, supervisory, and others, which can influence their perception of ELS (Gunasinghe et al., 2019). According to Li et al. (2021), social influence exerts a significant and positive effect on the students' intention to apply information technology. Likewise, Zhang et al. (2020) held the view that social influence is a critical factor in affecting technology usage and intention to adopt technology. Several researchers have explored the relationship of SI with BI in various contexts (Alzeban, 2016; Park et al., 2012; Teo \& Noyes, 2014; Yuan et al., 2015). Moreover, a positive link was found between SI and BI in the context of ELS (Ain et al., 2016; Tarhini et al., 2017; Zwain, 2019). Hence, the authors of this paper hypothesize the following statement:

H3: Social Influence positively affects Behavioral Intention to use E-Learning System.

\section{Hedonic Motivation (HM)}

A user's perceived level of enjoyment or entertainment resulting from using a specific technology is Hedonic Motivation (HM), which was added in the UTAUT2 by Venkatesh et al. (2012) to determine the role of intrinsic factors that motivate an individual to use technology. In the context of ELS, recent research conducted by AlAzawei and Alowayr (2020) stated that if students perceive using the system will be joyful, they will be more inclined to adopt it. Moreover, as the new generation is considered tech-savvy, they are more attracted to new technologies and find them entertaining. Thus, there will be a higher level of enjoyment resulting in the adoption of technology. Additionally, Nikolopoulou et al. (2021) claimed that teachers are highly motivated to adopt technology because of the hedonic motivation. As the teachers grow increasingly weary in traditional learning system, their intention to adopt the use of technology is fostered when they get entertained through technology. Hence, it is concluded that HM influenced secondary school teachers' BI to use mobile technology. Previous papers exploring HM have found a significant correlation with the adoption of innovative technology (Alalwan et al., 2015; ArenasGaitán et al., 2015). In the ELS context, researchers have found a positive link between HM and BI (Ain et al., 2016; El-Masri \& Tarhini, 2017; Gunasinghe et al., 2019; Tarhini et al., 2017; Teo \& Noyes, 2014; Raman \& Don, 2013; Zwain, 2019). Hence, the authors of this paper hypothesize the following statement:

H4: Hedonic Motivation positively affects Behavioral Intention to use E-Learning System.

\section{Habit (HB)}

The individual's degree of behaving consciously or unconsciously due to previous experience is known as Habit (HB) (Venkatesh et al., 2012). Further, Amalia et al. (2020) mentioned that habit reflects the experience, and when an individual frequently repeats that particular behavior, it is said to be a habit. Gunasinghe et al. (2019) said that HB is a user's cognitive commitment to performing a specific behavior, which also obstructs any behavioral changes. In other words, HB is the regular repetition of an individual's action because the individual is satisfied with the outcome. From the present study's perspective, if using the ELS becomes a student's habit, the individual will be more likely to adopt its use (Liu \& Liu, 2020). Venkatesh et al. (2012) revealed that people who frequently use electronic devices 
have more potential to adopt new technology. Prior studies in the ELS have shown that student's habitual behaviors towards ELS can increase the BI to use the system (El-Masri \& Tarhini, 2017; Gunasinghe et al., 2019; Zwain, 2019). Hence, the authors of this paper hypothesize the following statement:

H5: Habit positively affects Behavioral Intention to use E-Learning System.

\section{Facilitating Conditions (FC)}

The available infrastructure, technical and institutional support that assist individuals in using a specific innovative technology all come under the construct of Facilitating conditions (FC) (Venkatesh et al., 2012) and influence both intention and actual user behavior of technology. In other words, FC is the provision of resources essential for facilitating the performance of a specific behavior (Zhang et al., 2020). Further, Tandon (2020) specified that students are not against ELS, but they want their institutions and teachers to support them. Hence, when technical support is strong and students do not find any ELS glitches, the students are encouraged to adopt ELS. Many recent studies have evaluated the impact of FC on users' behavioral intention in various contexts. For instance, Ho et al. (2020) studied the factors facilitating or hindering the adoption of mobile banking. The results depicted that intention to adopt mobile banking is indirectly influenced by FC. In contrast, Kaur and Arora (2020) revealed that FC is positively associated with the intention to adopt online banking. Concerning the ELS context, FC is the students' understanding of the accessibility of the required resources needed to facilitate ELS use. Prior studies have revealed the critical impact of FCs on the adoption of technology in the ELS context (Ain et al., 2016; Gunasinghe et al., 2019; Tarhini et al., 2017). Hence, the authors of this paper hypothesize the following statement:

H6: Facilitating Conditions positively affects Behavioral Intention to use E-Learning System.

\section{Knowledge Acquisition (KA)}

Knowledge Acquisition (KA) is the process of acquiring new information to build upon the existing knowledge (Al-Emran et al., 2020; Al-Emran \& Teo, 2020). In the context of the present study, KA is the gaining of new knowledge through ELS. From a learning perspective, KA enables institutions to facilitate their process of learning. Hence, when institutions implement ELS, it improves the learning process. Also, students' eagerness to gain information follow the similar technologies, and this willingness increases their intention to adopt ELS (Zhang et al., 2020). GarcíaSánchez et al. (2017) revealed that KA positively influences the individuals' BI to use innovative technology. Al-Emran and Teo (2020) tested the ELS variable and established that KA has a direct and significant impact on the perceived usefulness and ease of use of ELS while indicating that it enhances students' willingness to use the technology. Similarly, Arpaci et al. (2020) claimed that knowledge management plays a major role in forming an intention to adopt MOOCs among engineering students. Therefore, we can predict that students are more likely to adopt online learning when they acquire knowledge based on prior research. Hence, the authors of this paper hypothesize the following statement: 
H7: Knowledge Acquisition positively affects Behavioral Intention to use E-Learning System.

\section{Knowledge Sharing (KS)}

Al-Emran and Teo (2020) explained that knowledge sharing (KS) is the practice of sharing or distributing various resources among individuals. In the ELS context, KS is sharing educational resources for the students' engagement in a learning activity to complete a course successfully. It is the exchange of experience and skills among students through the interaction in class from the educational perspective (Al-Emran et al., 2020). Additionally, students find knowledge sharing easy on online platforms. Without face-to-face interactions, they can share their knowledge with one another. Thus, this factor has played an essential role in fostering the use of online platforms (Wong \& Jeganathan, 2020). Choi et al. (2020) claimed that knowledge sharing through the online platform has gained massive attention as it allows users to share learning material without any difficulty. In other words, E-learning provides students a platform to share knowledge while enabling them to learn more efficiently. Several scholars have determined KS as an essential predictor of BI in the use of advanced technologies (Aboelmaged, 2018; Salloum et al., 2019). Furthermore, Al-Emran and Teo (2020) found that KS is able to positively affect the perceived utility and the ease of use in ELS; thus, they demonstrated how $\mathrm{KS}$ can encourage students to use technology. Hence, the following hypothesis is formed:

H8: Knowledge Sharing positively affects Behavioral Intention to use E-Learning System.

\section{Research Methodology}

\section{Research Model}

The factors from the original UTAUT2 model are incorporated into the research model. In addition, the authors have extended the model by adding KA and KS to explore further how these two variables can influence BI to use the ELS among students. The extended model has been illustrated in Figure 1.

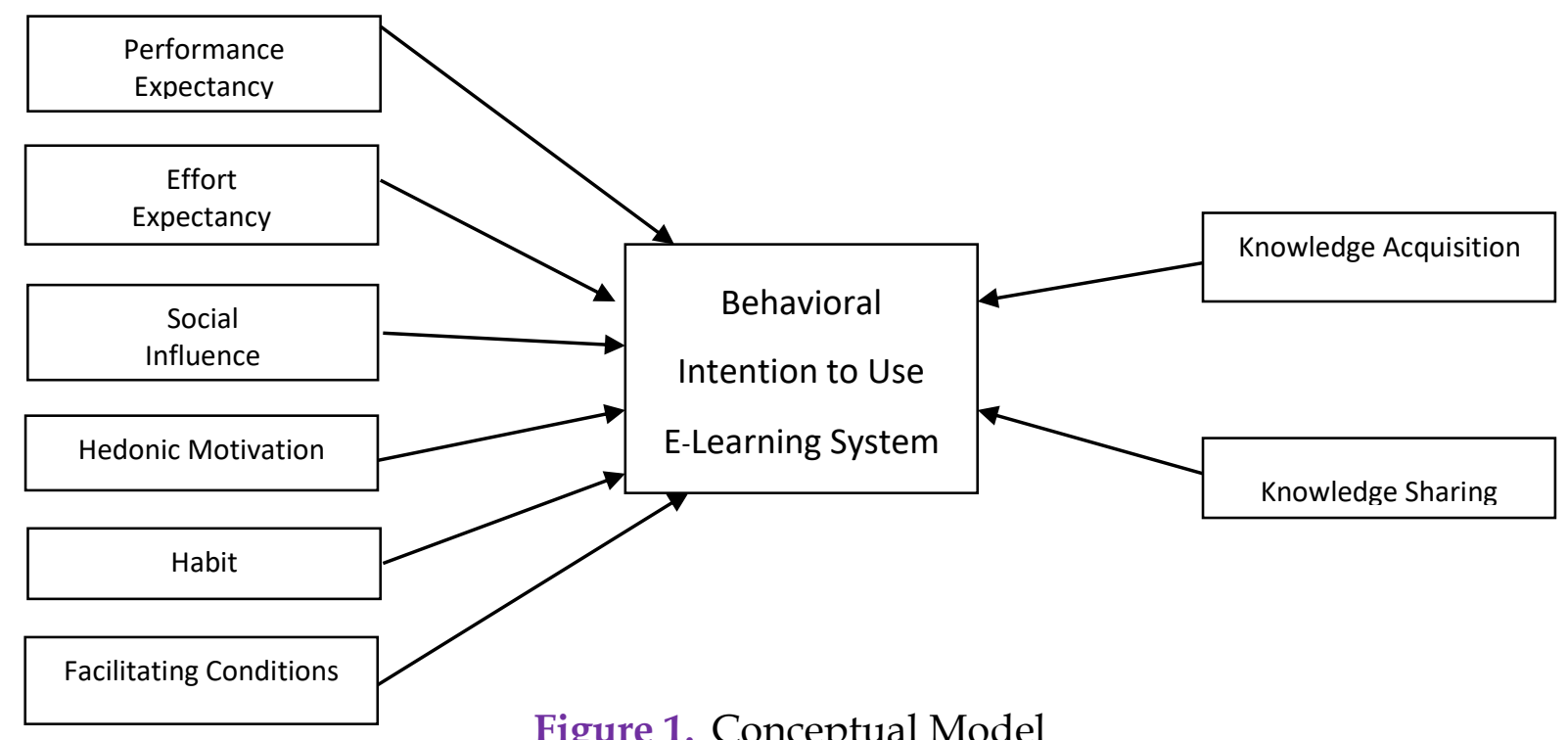

Figure 1. Conceptual Model 


\section{Data collection and Instrumentation}

The responses were collected by means of an online questionnaire, which collected a total of 508 responses. The sample size is based on the recommended sample size by Comrey and Lee (1992), who have determined that a poor sample size to be 50, a good sample size to be 300 , a very good sample size to be 500, and an excellent sample size of 1,000 for analysis. The collection of data for this research has been done in Pakistan, specifically from students enrolled in a private university in Karachi. The data has been collected by using a convenience sampling approach. The questionnaire was developed with a five-point Likert scale that ranges from "strongly disagree" to "strongly agree." The scale for data collection was developed by adopting items from the existing literature. The details of the instruments are mentioned in the table in the appendix.

\section{Demographics}

According to the demographic analysis results, the percentage of male respondents was 51.4 percent, while 48.6 percent of the respondents were females. The respondents' age analysis depicted that 50.8 percent were between the ages of 18-22, 28.7 percent were between the ages of 23-27, 19.3 percent were between the ages of 28-32, and only 1.2 percent were between the ages of 33-37. Furthermore, 75.6 percent of the respondents were undergraduates, while the remaining 24.4 percent were graduates.

Table 1. Respondents' Profile (N=508)

\begin{tabular}{lcc}
\hline Demographic Items & Frequency & Percentile \\
\hline Male & 261 & $51.4 \%$ \\
Female & 247 & $48.6 \%$ \\
Age & & \\
$\quad 18-22$ & 258 & $50.8 \%$ \\
$23-27$ & 146 & $28.7 \%$ \\
$28-32$ & 98 & $19.3 \%$ \\
$33-37$ & 6 & $1.2 \%$ \\
Education & & \\
$\quad$ Undergraduate & 384 & $75.6 \%$ \\
$\quad$ Graduate & 124 & $24.4 \%$ \\
\hline
\end{tabular}

Source: Author's Estimations

\section{Data Analysis and Results}

The data collected was analyzed by deploying a two-step approach: (a) using the Smart PLS 3.2.9 software; and (b) conducting PLS-SEM (Ringle et al., 2015; Qazi et al., 2020a). The measurement model was evaluated first. Thereafter, the structural model was assessed. Ringle et al. (2005) stated that a valid statistical technique to analyze the theory of a study through statistical facts and figures is Structural Equation Modeling (SEM). The variance-based method is deployed in the current study for analyzing the hypothetical model. Chin (1998) and Henseler et al. (2009) revealed that a suitable method for analyzing and examining an integrated model in distinct contexts for research purposes is executing PLS-SEM using Smart PLS software. 


\section{Measurement Model}

The scale used in this paper is assessed for its competency using the measurement model. The competency of the scale can be measured through analyzing the scale's Composite Reliability (CR), Individual Item Reliability (IIR), Convergent Validity (CV), and the Average Variance Extracted (AVE).

The value that is obtained to determine the instrument's reliability is called Cronbach's alpha. Its criterion is given by Tabachnick and Fiddell (2007). They said that the value should be more than 0.55, and the Cronbach value in Table 2 shows that it meets the criteria, indicating that the scale is reliable for analysis. Moreover, Table 2 also depicts that the value of the CR is more significant than 0.7 , which meets the criteria given by Straub (1989). Since the benchmark for IIR is 0.7 (Ahmed et al., 2021; Churchill, 1979), the tool has been considered reliable for research as the value of IIR is greater than 0.7 in Table 2 . The results also show that each variable has an AVE higher than 0.5 , confirming the CV of the scale as it meets the criteria (Fornell \& Larcker, 1981, Qazi et al., 2020b).

Table 2. Measurement Model Results

\begin{tabular}{|c|c|c|c|c|c|}
\hline & Items & Loadings & Cronbach's Alpha & $\begin{array}{l}\text { Composite } \\
\text { Reliability }\end{array}$ & $\begin{array}{c}\text { Average Variance } \\
\text { Extracted }\end{array}$ \\
\hline \multirow{4}{*}{ BI } & BI1 & 0.762 & & & \\
\hline & BI2 & 0.847 & 0.808 & 0.874 & 0.635 \\
\hline & BI3 & 0.812 & & & \\
\hline & BI4 & 0.764 & & & \\
\hline \multirow{5}{*}{ EE } & EE1 & 0.728 & & & \\
\hline & EE2 & 0.724 & & & \\
\hline & EE3 & 0.827 & 0.860 & 0.879 & 0.595 \\
\hline & EE4 & 0.868 & & & \\
\hline & EE5 & 0.951 & & & \\
\hline \multirow{4}{*}{ FC } & FC1 & 0.913 & & & \\
\hline & FC2 & 0.926 & 0.701 & 0.882 & 0.605 \\
\hline & FC3 & 0.785 & & & \\
\hline & FC4 & 0.701 & & & \\
\hline \multirow{3}{*}{ HB } & HB1 & 0.891 & & & \\
\hline & HB2 & 0.930 & 0.901 & 0.937 & 0.833 \\
\hline & HB3 & 0.917 & & & \\
\hline \multirow{3}{*}{ HM } & HM1 & 0.929 & & & \\
\hline & HM2 & 0.953 & 0.803 & 0.789 & 0.565 \\
\hline & HM3 & 0.712 & & & \\
\hline \multirow{5}{*}{ KA } & KA1 & 0.816 & & & \\
\hline & KA2 & 0.814 & & & \\
\hline & KA3 & 0.962 & 0.867 & 0.730 & 0.714 \\
\hline & KA4 & 0.880 & & & \\
\hline & KA5 & 0.974 & & & \\
\hline \multirow{5}{*}{ KS } & KS1 & 0.758 & & & \\
\hline & KS2 & 0.858 & & & \\
\hline & KS3 & 0.826 & 0.863 & 0.901 & 0.647 \\
\hline & KS4 & 0.826 & & & \\
\hline & KS5 & 0.747 & & & \\
\hline
\end{tabular}


Table 2. Continued.

\begin{tabular}{cccccc}
\hline & Items & Loadings & Cronbach's Alpha & $\begin{array}{c}\text { Composite } \\
\text { Reliability }\end{array}$ & $\begin{array}{c}\text { Average Variance } \\
\text { Extracted }\end{array}$ \\
\hline \multirow{4}{*}{ PE } & PE1 & 0.821 & & & \\
& PE2 & 0.845 & & & 0.550 \\
& PE3 & 0.865 & 0.756 & & \\
& PE4 & 0.780 & & & \\
& PE5 & 0.889 & & 0.834 & \\
& SI1 & 0.762 & & & \\
& SI2 & 0.846 & & & \\
\hline & SI3 & 0.812 & 0.711 & & \\
& SI4 & 0.764 & & & \\
& SI5 & 0.823 & & & \\
&
\end{tabular}

Notes: BI=Behavioral Intention, EE=Effort Expectancy, $F C=$ Facilitating Conditions, $P E=$ Performance Expectancy, SI=Social Influence, HB=Habit, HM=Hedonic Motivation, KA=Knowledge Acquisition, KS=Knowledge Sharing.

Based on the analysis of discriminant validity in Table 3, the values have been measured through cross-loading analysis and extraction of the AVE in accordance to the criteria set by Fornell and Larker (1981). With respect to the criteria, the value of AVE must be higher than the correlation of the variables. This has been met as displayed through the diagonal representation of the values in Table 3 as the square root of AVE satisfies the given criteria (Raza et al., 2020).

Table 3. Fornell-Larker Criteria

\begin{tabular}{cccccccccc}
\hline & BI & EE & FC & HB & HM & KA & KS & PE & SI \\
\hline BI & $\mathbf{0 . 7 9 7}$ & & & & & & & & \\
EE & -0.085 & $\mathbf{0 . 7 7 1}$ & & & & & & & \\
FC & 0.080 & -0.180 & $\mathbf{0 . 7 7 8}$ & & & & & & \\
HB & -0.036 & 0.008 & 0.021 & $\mathbf{0 . 9 1 3}$ & & & & & \\
$\mathbf{H M}$ & -0.027 & -0.027 & 0.023 & 0.654 & $\mathbf{0 . 7 5 2}$ & & & & \\
KA & 0.126 & -0.018 & -0.010 & -0.032 & -0.027 & $\mathbf{0 . 8 4 5}$ & & \\
KS & 0.537 & -0.126 & 0.032 & -0.134 & -0.109 & 0.136 & $\mathbf{0 . 8 0 4}$ & & \\
PE & 0.377 & 0.002 & 0.016 & -0.121 & -0.164 & 0.144 & 0.394 & $\mathbf{0 . 7 4 1}$ & \\
SI & 1.000 & -0.091 & 0.102 & -0.032 & -0.022 & 0.125 & 0.536 & 0.376 & $\mathbf{0 . 7 1 4}$ \\
\hline Notes: BI=Behavioral Intention, EE=Effort Expectancy, FC=Facilitating Conditions, PE=Performance Expectancy, \\
SI=Social Influence, HB=Habit, HM=Hedonic Motivation, KA=Knowledge Acquisition, KS=Knowledge Sharing.
\end{tabular}

The discriminant validity is represented in Table 4, the values of which are higher than 0.1; hence, meeting the criteria given by Gefen and Straub (2005). Furthermore, it can be seen that each item is loaded higher in their relevant factors due to the presence of the cross-loading difference. This indicates the confirmation of the discriminant validity of the model.

Table 4. Loadings and Cross Loadings

\begin{tabular}{cccccccccc}
\hline & BI & EE & FC & HB & HM & KA & KS & PE & SI \\
\hline BI1 & $\mathbf{0 . 7 6 2}$ & -0.080 & 0.051 & 0.015 & 0.035 & 0.086 & 0.406 & 0.223 & 0.762 \\
BI2 & $\mathbf{0 . 8 4 7}$ & -0.045 & 0.073 & -0.044 & -0.052 & 0.114 & 0.442 & 0.265 & 0.846 \\
BI3 & $\mathbf{0 . 8 1 2}$ & -0.068 & 0.055 & -0.058 & -0.046 & 0.146 & 0.454 & 0.413 & 0.812 \\
BI4 & $\mathbf{0 . 7 6 4}$ & -0.082 & 0.077 & -0.024 & -0.016 & 0.053 & 0.410 & 0.298 & 0.764 \\
EE1 & -0.065 & $\mathbf{0 . 7 2 8}$ & -0.235 & 0.037 & -0.004 & -0.015 & -0.051 & 0.045 & -0.071 \\
\hline
\end{tabular}


Table 4. Continued.

\begin{tabular}{|c|c|c|c|c|c|c|c|c|c|}
\hline & BI & $\mathrm{EE}$ & FC & HB & HM & KA & KS & PE & SI \\
\hline EE2 & -0.001 & 0.724 & -0.065 & -0.051 & -0.089 & -0.005 & -0.077 & 0.047 & -0.004 \\
\hline EE3 & -0.060 & 0.827 & -0.101 & -0.018 & -0.039 & -0.030 & -0.134 & -0.054 & -0.063 \\
\hline EE4 & -0.078 & 0.868 & -0.103 & -0.002 & -0.023 & -0.004 & -0.122 & 0.006 & -0.081 \\
\hline EE5 & 0.004 & 0.951 & -0.084 & -0.027 & -0.028 & -0.028 & -0.092 & 0.000 & 0.001 \\
\hline FC1 & 0.064 & -0.171 & 0.913 & 0.117 & 0.132 & 0.011 & 0.028 & -0.012 & 0.086 \\
\hline FC2 & 0.076 & -0.162 & 0.926 & 0.175 & 0.217 & -0.031 & -0.009 & -0.007 & 0.096 \\
\hline FC3 & -0.023 & 0.001 & 0.785 & 0.612 & 0.739 & -0.004 & -0.111 & -0.104 & -0.018 \\
\hline FC4 & -0.006 & 0.018 & 0.701 & 0.628 & 0.773 & -0.042 & -0.089 & -0.138 & -0.002 \\
\hline HB1 & -0.027 & -0.016 & -0.003 & 0.891 & 0.606 & -0.038 & -0.088 & -0.123 & -0.022 \\
\hline HB2 & -0.035 & 0.012 & 0.042 & 0.930 & 0.590 & -0.011 & -0.136 & -0.127 & -0.032 \\
\hline HB3 & -0.036 & 0.020 & 0.012 & 0.917 & 0.599 & -0.040 & -0.135 & -0.085 & -0.033 \\
\hline HM1 & -0.020 & 0.002 & 0.032 & 0.591 & 0.929 & -0.025 & -0.093 & -0.145 & -0.015 \\
\hline HM2 & 0.007 & -0.078 & 0.036 & 0.572 & 0.953 & -0.091 & -0.071 & -0.098 & 0.012 \\
\hline HM3 & -0.015 & -0.086 & 0.012 & 0.584 & 0.712 & -0.057 & -0.094 & -0.129 & -0.010 \\
\hline KA1 & 0.068 & -0.040 & -0.016 & -0.044 & -0.036 & 0.816 & 0.110 & 0.095 & 0.066 \\
\hline KA2 & 0.037 & -0.124 & 0.013 & -0.011 & -0.033 & 0.814 & 0.124 & 0.083 & 0.036 \\
\hline KA4 & -0.059 & -0.105 & -0.002 & -0.057 & -0.029 & 0.880 & 0.067 & 0.017 & -0.060 \\
\hline KA3 & 0.000 & -0.115 & 0.020 & -0.047 & -0.046 & 0.962 & 0.104 & 0.049 & -0.001 \\
\hline KA5 & 0.034 & -0.010 & -0.012 & -0.076 & -0.011 & 0.974 & 0.096 & 0.104 & 0.033 \\
\hline KS1 & 0.361 & -0.126 & 0.016 & -0.098 & -0.079 & 0.100 & 0.758 & 0.335 & 0.360 \\
\hline KS2 & 0.445 & -0.100 & -0.011 & -0.118 & -0.125 & 0.114 & 0.858 & 0.391 & 0.443 \\
\hline KS3 & 0.403 & -0.053 & 0.032 & -0.126 & -0.134 & 0.088 & 0.826 & 0.318 & 0.402 \\
\hline KS4 & 0.406 & -0.092 & -0.004 & -0.119 & -0.082 & 0.086 & 0.826 & 0.333 & 0.405 \\
\hline KS5 & 0.510 & -0.131 & 0.085 & -0.082 & -0.029 & 0.146 & 0.747 & 0.222 & 0.511 \\
\hline PE1 & 0.293 & 0.064 & 0.005 & -0.116 & -0.182 & 0.107 & 0.308 & 0.821 & 0.291 \\
\hline PE2 & 0.337 & 0.089 & 0.007 & -0.134 & -0.144 & 0.144 & 0.354 & 0.845 & 0.336 \\
\hline PE3 & 0.298 & 0.030 & 0.031 & -0.069 & -0.133 & 0.095 & 0.303 & 0.865 & 0.297 \\
\hline PE4 & 0.307 & -0.084 & -0.024 & -0.078 & -0.096 & 0.128 & 0.323 & 0.780 & 0.305 \\
\hline PE5 & -0.048 & 0.631 & -0.213 & -0.013 & -0.066 & 0.008 & -0.053 & 0.889 & -0.054 \\
\hline SI1 & 0.762 & -0.080 & 0.051 & 0.015 & 0.035 & 0.086 & 0.406 & 0.223 & 0.762 \\
\hline SI2 & 0.847 & -0.045 & 0.073 & -0.044 & -0.052 & 0.114 & 0.442 & 0.265 & 0.846 \\
\hline SI3 & 0.812 & -0.068 & 0.055 & -0.058 & -0.046 & 0.146 & 0.454 & 0.413 & 0.812 \\
\hline SI4 & 0.764 & -0.082 & 0.077 & -0.024 & -0.016 & 0.053 & 0.410 & 0.298 & 0.764 \\
\hline SI5 & 0.071 & -0.200 & 0.797 & 0.145 & 0.169 & -0.043 & -0.001 & -0.016 & 0.823 \\
\hline
\end{tabular}

Table 5 of the measurement model, which shows the heterotrait-monotrait ratio of correlations (HTMT), indicates that the values are below 0.85. Thus, it confirms the validity of the model according to the prescribed criterion (Henseler et al., 2015; Khaskheli et al., 2020).

Table 5. Heterotrait-Monotrait Ratio (HTMT)

\begin{tabular}{|c|c|c|c|c|c|c|c|c|c|}
\hline & BI & EE & FC & HВ & HM & KA & KS & PE & SI \\
\hline \multicolumn{10}{|l|}{ BI } \\
\hline $\mathrm{EE}$ & 0.075 & & & & & & & & \\
\hline FC & 0.103 & 0.166 & & & & & & & \\
\hline HB & 0.052 & 0.041 & 0.664 & & & & & & \\
\hline
\end{tabular}


Table 5. Continued.

\begin{tabular}{|c|c|c|c|c|c|c|c|c|c|}
\hline & BI & $\mathrm{EE}$ & FC & HB & HM & KA & KS & PE & SI \\
\hline HM & 0.043 & 0.107 & 0.798 & 0.811 & & & & & \\
\hline KA & 0.080 & 0.123 & 0.067 & 0.071 & 0.115 & & & & \\
\hline KS & 0.633 & 0.137 & 0.135 & 0.150 & 0.125 & 0.143 & & & \\
\hline PE & 0.459 & 0.307 & 0.197 & 0.145 & 0.210 & 0.111 & 0.468 & & \\
\hline SI & 0.598 & 0.141 & 0.376 & 0.106 & 0.122 & 0.101 & 0.649 & 0.493 & \\
\hline
\end{tabular}

Notes: $B I=$ Behavioral Intention, EE=Effort Expectancy, $F C=$ Facilitating Conditions, PE=Performance Expectancy, $S I=$ Social Influence, $H B=H a b i t, H M=H e d o n i c$ Motivation, $K A=$ Knowledge Acquisition, $K S=K n o w l e d g e$ Sharing

\section{Structural Model}

The results were found using the structural model analysis in which standardized paths were analyzed in correspondence with the hypotheses of this study. The outcomes of the analysis are depicted in Table 6 and Figure 2.

Table 6. Results of Path Analysis.

\begin{tabular}{ccccc}
\hline Hypothesis & Regression Path & Effect type & SRW & Remarks \\
\hline H1 & PE $>$ BI & Direct Effect & $0.652^{* * *}$ & Supported \\
H2 & EE $>$ BI & Direct Effect & $0.337^{* *}$ & Supported \\
H3 & SI $>$ BI & Direct Effect & $1.002^{* * *}$ & Supported \\
H4 & HM $>$ BI & Direct Effect & -0.552 & Not Supported \\
H5 & HB $>$ BI & Direct Effect & $0.246^{* *}$ & Supported \\
H6 & FC $>$ BI & Direct Effect & $0.217^{* * *}$ & Supported \\
H7 & KA $>$ BI & Direct Effect & $0.468^{* * *}$ & Supported \\
H8 & KS $>$ BI & Direct Effect & $0.516^{* * *}$ & Supported \\
\hline
\end{tabular}

${ }^{* * *} P<0.01, " * P<0.05$

Notes: BI=Behavioral Intention, EE=Effort Expectancy, FC=Facilitating Conditions, PE=Performance Expectancy, SI=Social Influence, $H B=H a b i t, H M=H e d o n i c$ Motivation, $K A=$ Knowledge Acquisition, KS=Knowledge Sharing.

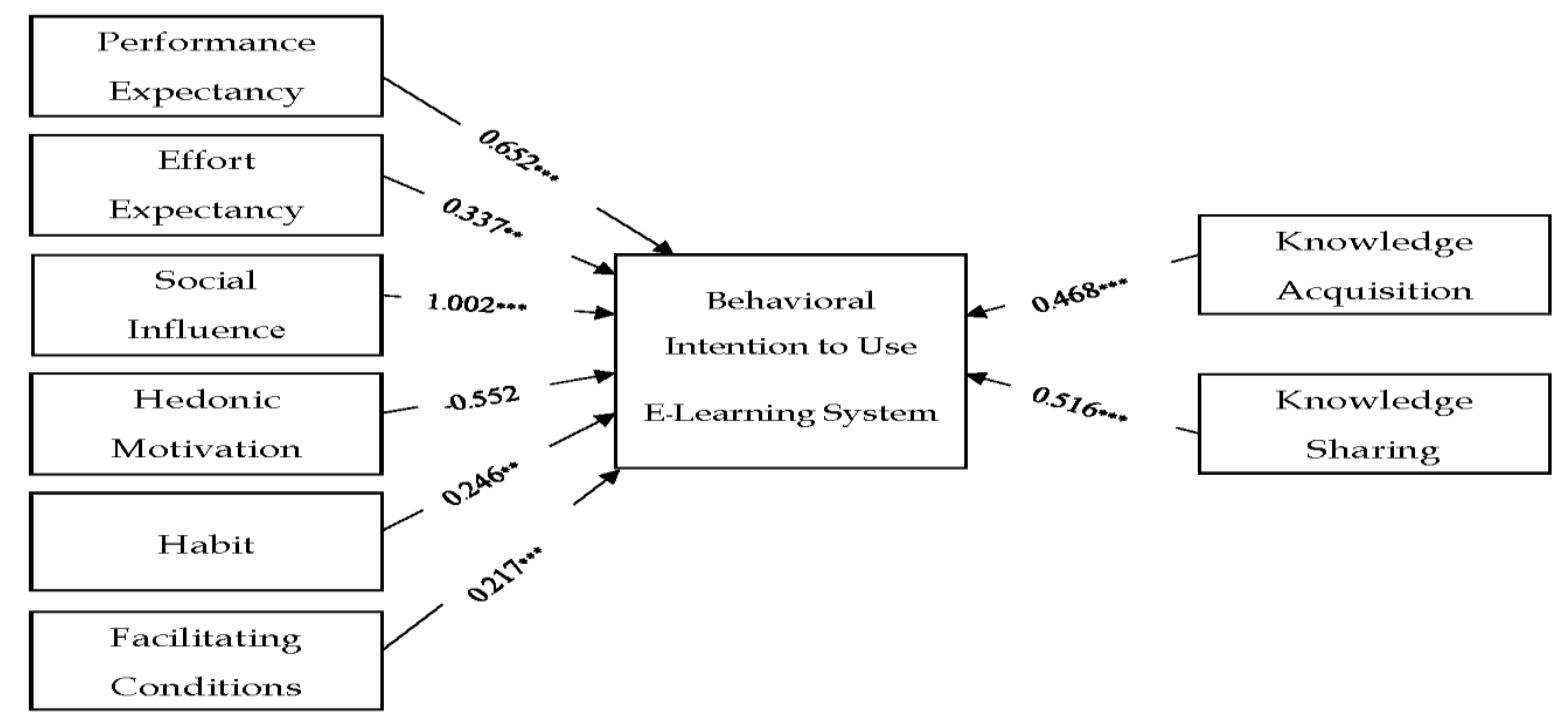

Figure 2. Results of Path Analysis 


\section{DISCUSSION}

Based on the analysis outcomes depicted in Table 6, the hypotheses concerning PE, EE, SI, and FC with BI have been accepted. These constructs were the primary factors of the UTUAT model and showed that they have a positive link with the students' BI, revealing that if students believe their performance will be improved without extra effort, they will likely adopt the use of the ELS. Likewise, the encouraging influence of social groups and the availability of proper infrastructure and support will promote ELS adoption. The result is consistent with the outcomes of Gunasinghe et al. (2019), except for SI, which was found to be an insignificant predictor. In contrast, Zwain (2019) found SI a significant predictor, while the other constructs were not supported. Meanwhile, Ain et al. (2016) only found PE and SI as significant predictors, while EE and FC were declared insignificant. The results depict that students are ready to adopt ELS if institutions support and understand that a sudden change in learning methodologies needs time. However, if students learn ELS and understand the benefits of e-learning, they will ultimately foster their BI to use ELS. Before the pandemic, there was no online learning trend, but now many people are enrolled in online programs and prefer to take online classes in university (Shehzadi et al., 2020).

Similarly, the hypotheses concerning the relationship of HB with BI have also been accepted. Meaning, if the students are in the habit of using electronic devices for their learning purposes, they will be more likely to adopt the ELS. It shows that students are now becoming aware of the ELS, making them habitual in using ELS as time passes. Initially, when the pandemic first started, students found it difficult to take online classes (Raza et al., 2021), but now the situation is different, and that is why ELS has a vast scope in Pakistan. This result is consistent with the previous studies (Gunasinghe et al., 2019; Zwain, 2019) but inconsistent with the outcomes of Ain et al. (2015), who have determined that HB did not influence BI.

In contrast, the affiliation between HM and BI in using the ELS was negative, which indicates that the hypothesis is not supported. This means that students do not perceive ELS as a source of enjoyment and entertainment; rather, they view it just as a source for acquiring knowledge for their course completion. Also, students in developing states find social networking sites and friends or family meetups an entertaining source. ELS is a newly introduced platform in Pakistan, and it has only been used for educational purposes. Some restrictions and loopholes make the students reluctant to explore further, and it results in a negative association. This result is inconsistent with the findings of prior studies (Gunasinghe et al., 2019; Zwain, 2019); however, they are consistent with the findings of Ain et al. (2015).

Moreover, the hypotheses concerning the knowledge management factors that include KA and KS are also found to be directly associated with the students' BI to use the ELS. This may be attributed to the increased convenience of online acquiring and sharing knowledge resources (Raza \& Khan, 2021). This indicates that students BI to use ELS will likely increase if they can acquire and share knowledge by using the system. The findings confirm that students of an emerging state are also willing to adopt ELS based on knowledge management factors. In today's era, students are multitaskers, and they want to avail themselves with the maximum benefits in a short period. Hence, the pandemic has provided them a great opportunity for online 
education. So, if students acquire and share knowledge through ELS, it will foster behavioral intention to use ELS. The results are consistent with the findings of the existing literature (Aboelmaged 2018; Al-Emran \& Teo, 2020; García-Sánchez et al. 2017; Salloum et al. 2019)

\section{CONCLUSION}

The purpose of this study is to recognize the critical factors for ELS adoption among students in Pakistan due to the dire need for the successful execution of ELS in developing countries as it is an educational tool without the constraints of time, distance and resources. The study explores the extended model of UTAUT2 by adding knowledge management factors, including KA and KS, to investigate how these factors influence ELS adoption. The integration of the knowledge constructs in the hypothesized model intensifies the model's relevance to the context of ELS as the system provides the tools for convenient acquisition and sharing of knowledge. The empirical findings generated from the analysis show that PE, EE, SI, HB, FC, KA, and KS directly link with students' BI to use ELS. The results in this paper offer valuable insights into the factors required to influence the BI of adoption of ELS among the students enrolled in Pakistani universities. These findings are valuable for practitioners, policymakers, decision-makers, and university management for the successful development and integration of ELS.

The findings drawn from this research have some theoretical and practical implications. This paper's implications for theory are confined to the development of an extended UTAUT2 model to identify what factors influence students' acceptance of ELS. By integrating two prominent variables related to knowledge management, which is an essential part of ELS, the extension has provided a deep understanding of technology acceptance. Moreover, we have developed a validated survey for analysis by adopting items from the existing literature that can be used to apply in different contexts to explore students' willingness in adopting ELS. While Venkatesh et al. (2012) stressed the significance of using the UTAUT2 model in various cultures and contexts to enhance the model's validity and generalizability, its applicability remains gravely limited in education settings. Filling this gap, this study has contributed to the existing literature by exploring factors essential for understanding how BI is related to the use of ELS in a developing country. Additionally, this research has been conducted after the sudden change in teaching methodologies due to the pandemic; hence, we have sought to understand students' BI to use EIS so that literature in this field can be extended and new theoretical insights can be generated.

As for the practical implications of this paper, it is essential to highlight that the successful implementation and use of the ELS would enable Pakistani universities to overcome issues found in a traditional classroom such as a lack of space, time, and resources. Besides, since ELS is a newly introduced concept, many people are finding it difficult to use. The authors of this paper recommend that those institutions in Pakistan working on developing ELS should consider the findings of this research project in their planning and decision-making process for successful implementation. Since the findings directly correlate with all the factors except HM, a focus on these areas is required. A periodic review of the ELS can enable them to understand the flaws that need improvement for PE and EE. Opportunities should 
be offered to students to gain first-hand experience in using ELS, which will enable them to understand its benefits, leading to a higher adoption rate. Moreover, the system should be developed to be user-friendly, and a helpdesk should be provided to help students gain experience through using the system, which could develop their HB through trial and use. Policymakers and academicians need to implement ELS by enabling students to acquire knowledge and share it anytime and anywhere to develop their BI to use ELS. Lastly, the management and administrators should develop FC by providing the necessary means for the students to adopt the use of ELS with a changed perception as they will discover how it saves their time and cost. The results also indicate that SI is a major influencing factor for BI to use ELS; therefore, academicians, lecturers, and other university management personnel can promote the use of ELS by supporting and encouraging the students in using it. The major contribution of the existing research is that it evaluates students' BI to use ELS after their first exposure. However, due to the lockdown precipitated by the Covid19 pandemic, almost all universities conduct online classes. This inadvertently offers an interesting area for this research to study the impact of UTAUT factors and knowledge management on students' BI to use ELS. Thus, this paper has sought to expand the theory as well. Moreover, it targets the higher education students as they are aware of the ELS crackups and benefits.

Finally, with the limitations encountered in this study, this paper identifies potential directions for future research. Firstly, this research focuses only on the students' BI to use ELS without targeting the academicians, the faculty, or other ELS stakeholders. Hence, we recommend that future scholars should target the faculty as it will offer a new insight into whether its members are willing to adopt ELS and be adequately trained for it. Secondly, this study is based on a quantitative method, limiting the insights that can be gained from qualitative or mixed-method studies. Hence, other methods could be employed for the expansion of the present study. Thirdly, it is recommended that researchers should conduct a comparative analysis between a developing and developed country to find out how both economies conduct online education during and after the pandemic and the students' behavior under such circumstances. Finally, the model does not consist any moderating and mediating variables that could theoretically impact the constructs discussed in this paper. Hence, future studies can focus on analyzing mediation and moderation.

\section{REFERENCES}

Aboelmaged, M.G. (2018). Knowledge sharing through enterprise social network (ESN) systems: motivational drivers and their impact on employees' productivity. Journal of Knowledge Management.

Abbad, M.M. (2021). Using the UTAUT model to understand students' usage of elearning systems in developing countries. Education and Information Technologies, 1-20.

Agrawal, V., Agrawal, A., \& Agarwal, S. (2016). Assessment of factors for e-learning: an empirical investigation. Industrial and Commercial Training.

Ahmed, M., Guo, Q., Qureshi, M.A., Raza, S.A., Khan, K.A., \& Salam, J. (2021). Do green HR practices enhance green motivation and proactive environmental 
management maturity in hotel industry?. International Journal of Hospitality Management, 94, 102852.

Ain, N., Kaur, K., \& Waheed, M. (2016). The influence of learning value on learning management system use: An extension of UTAUT2. Information Development, 32(5), 1306-1321.

Ajzen, I. (2012). Behavioral interventions based on the theory of planned behavioronlinene).

Ajzen, I. (1991). The theory of planned behavior. Organizational behavior and human decision processes, 50(2), 179-211.

Altalhi, M. (2021). Toward a model for acceptance of MOOCs in higher education: the modified UTAUT model for Saudi Arabia. Education and Information Technologies, 26(2), 1589-1605.

Al-Azawei, A., \& Alowayr, A. (2020). Predicting the intention to use and hedonic motivation for mobile learning: A comparative study in two Middle Eastern countries. Technology in Society, 62, 101325.

Alalwan, A.A., Dwivedi, Y.K., Rana, N.P., Lal, B., \& Williams, M.D. (2015). Consumer adoption of Internet banking in Jordan: Examining the role of hedonic motivation, habit, self-efficacy, and trust. Journal of Financial Services Marketing, 20(2), 145-157.

Alalwan, A.A., Dwivedi, Y.K., \& Williams, M.D. (2014, April). Examining Factors Affecting Customer Intention And Adoption Of Internet Banking In Jordan. In UKAIS (p. 3).

Ali, Z., Gongbing, B., \& Mehreen, A. (2018). Understanding and predicting academic performance through cloud computing adoption: a perspective of the technology acceptance model. Journal of Computers in Education, 5(3), 297-327.

Al-Busaidi, K.A. (2012). Learners' perspective on critical factors to LMS success in blended learning: An empirical investigation. Communications of the Association for Information Systems, 30(1), 2.

Al-Busaidi, K.A. (2013). An empirical investigation linking learners' adoption of blended learning to theiIntentionon of full e-learning. Behaviour $\mathcal{E}$ Information Technology, 32(11), 1168-1176.

Al-Emran, M., Mezhuyev, V., \& Kamaludin, A. (2020). Towards a conceptual model for examining the impact of knowledge management factors on mobile learning acceptance. Technology in Society, 101247.

Al-Emran, M., \& Teo, T. (2020). Do knowledge acquisition and knowledge sharing really affect e-learning adoption? An empirical study. Education and Information Technologies, 25(3), 1983-1998.

Alqirim, M., Serhani, M., Rouibah, K. and Tarhini, A. (2017), "Towards a Personality Understanding of Information Technology Students and their IT Learning in UAE University", Education and Information Technologies, pp. 1-18.

Alfraih, M.M., \& Alanezi, F.S. (2016). Accounting students' perceptions of effective faculty attributes. Journal of International Education in Business.

Alsabawy, A.Y., Cater-Steel, A., \& Soar, J. (2016). Determinants of perceived usefulness of e-learning systems. Computers in Human Behavior, 64, 843-858.

Althunibat, A. (2015). Determining the factors influencing studentsIntentionon to use m-learning in Jordan higher education. Computers in Human Behavior, 52, 65-71. 
Al Imarah, A., Zwain, A., \& Al-Hakim, L. (2013). The adoption of e-government services in the Iraqi Higher Education Context: An application of the UTAUT model in the University of Kufa. Journal of Information Engineering and Applications, 3(10), 77-84.

Al-Maroof, R.S., \& Salloum, S.A. (2021). An Integrated model of continuous intention to use of google classroom. In Recent Advances in Intelligent Systems and Smart Applications (pp. 311-335). Springer, Cham.

Alzeban, A. (2016). Factors influencing adoption of the international financial reporting standards (IFRS) in accounting education. Journal of International Education in Business.

Amalia, F.A., Sosianika, A., \& Suhartanto, D. (2020). Indonesian Millennials' Halal food purchasing: merely a habit?. British Food Journal.

Anwar, M., Khan, A., \& Sultan, K. (2020). The Barriers and Challenges Faced by Students in Online Education during Covid-19 Pandemic in Pakistan. Gomal University Journal of Research, 36(1), 52-62.

Arenas Gaitán, J., Peral Peral, B., \& Ramón Jerónimo, M. (2015). Elderly and internet banking: An application of UTAUT2. Journal of Internet Banking and Commerce, $20(1), 1-23$.

Arpaci, I., Al-Emran, M., \& Al-Sharafi, M.A. (2020). The impact of knowledge management practices on the acceptance of Massive Open Online Courses (MOOCs) by engineering students: A cross-cultural comparison. Telematics and informatics, 54, 101468.

Chin, W.W. (1998). The partial least squares approach to structural equation modeling. Modern methods for business research, 295(2), 295-336.

Choi, G., Nam, C., Kim, S., Jung, H. J., \& Lee, C. H. (2020). Where does knowledgesharing motivation come from? The case of third-party developer in mobile platforms. Journal of Knowledge Management.

Churchill Jr, G.A. (1979). A paradigm for developing better measures of marketing constructs. Journal of marketing research, 16(1), 64-73.

Clay, M.N., Rowland, S., \& Packard, A. (2008). Improving undergraduate online retention through gated advisement and redundant communication. Journal of College Student Retention: Research, Theory E Practice, 10(1), 93-102.

Comrey, A. L., \& Lee, H. B. (1992). Interpretation and application of factor analytic results. Comrey AL, Lee HB. A first course in factor analysis, 2, 1992.

Davis, F.D. (1989). Perceived usefulness, perceived ease of use, and user acceptance of information technology. MIS quarterly, 319-340.

Driscoll, M. (2002). Blended learning: Let's get beyond the hype. E-learning, 1(4), 1-4.

El-Masri, M., \& Tarhini, A. (2017). Factors affecting the adoption of e-learning systems in Qatar and USA: Extending the Unified Theory of Acceptance and Use of Technology 2 (UTAUT2). Educational Technology Research and Development, 65(3), 743-763.

Fishbein, M., \& Ajzen, I. (1975). Intention and Behavior: An introduction to theory and research.

Fornell, C., \& Larcker, D.F. (1981). Evaluating structural equation models with unobservable variables and measurement error. Journal of marketing research, 18(1), 39-50. 
García-Sánchez, E., García-Morales, V.J., \& Bolívar-Ramos, M.T. (2017). The influence of top management support for ICTs on organisational performance through knowledge acquisition, transfer, and utilisation. Review of Managerial Science, 11(1), 19-51.

Garone, A., Pynoo, B., Tondeur, J., Cocquyt, C., Vanslambrouck, S., Bruggeman, B., \& Struyven, K. (2019). Clustering university teaching staff through UTAUT: Implications for the acceptance of a new learning management system. British Journal of Educational Technology, 50(5), 2466-2483

Gefen, D., \& Straub, D. (2005). A practical guide to factorial validity using PLSGraph: Tutorial and annotated example. Communications of the Association for Information systems, 16(1), 5.

Global Market Insights (2019), "eLearnnig trends", available at: www.globenewswire.com/newsrelease/2019/03/06/1748554/0/en/E-

Learning-Market to-surpass-300bn-by-2025-Global-MarketInsights-Inc.htm

Gruzd, A., Staves, K., \& Wilk, A. (2012). Connected scholars: Examining the role of social media in research practices of faculty using the UTAUT model. Computers in Human Behavior, 28(6), 2340-2350.

Gunasinghe, A., Hamid, J.A., Khatibi, A., \& Azam, S.F. (2019). The adequacy of UTAUT-3 in interpreting academician's adoption to e-Learning in higher education environments. Interactive Technology and Smart Education.

Henseler, J., Ringle, C.M., \& Sinkovics, R.R. (2009). The use of partial least squares path modeling in international marketing. In New challenges to international marketing. Emerald Group Publishing Limited.

Henseler, J., Ringle, C.M., \& Sarstedt, M. (2015). A new criterion for assessing discriminant validity in variance-based structural equation modeling. Journal of the academy of marketing science, 43(1), 115-135.

Ho, J. C., Wu, C.G., Lee, C.S., \& Pham, T.T.T. (2020). Factors affecting the behavioral intention to adopt mobile banking: An international comparison. Technology in Society, 63, 101360.

Islam, A.N. (2016). E-learning system use and its outcomes: Moderating role of perceived compatibility. Telematics and Informatics, 33(1), 48-55.

Joa, C.Y., \& Magsamen-Conrad, K. (2021). Social influence and UTAUT in predicting digital immigrants' technology use. Behaviour \& Information Technology, 1-19.

Khaskheli, A., Jiang, Y., Raza, S.A., Qureshi, M.A., Khan, K.A., \& Salam, J. (2020). Do CSR activities increase organizational citizenship behavior among employees? Mediating role of affective commitment and job satisfaction. Corporate Social Responsibility and Environmental Management, 27(6), 2941-2955.

Kaur, S. and Arora, S. (2021), "Role of perceived risk in online banking and its impact on behavioral intention: trust as a moderator", Journal of Asia Business Studies, Vol. 15 No. 1, pp. 1-30. https:// doi.org/10.1108/JABS-08-2019-0252

Liaw, S.S., \& Huang, H.M. (2011, May). A study of investigating learners attitudes toward e-learning. In $5^{\text {th }}$ International Conference on Distance Learning and Education (Vol. 12, pp. 28-32).

Li, C., He, L., \& Wong, I.A. (2021). Determinants predicting undergraduates' intention to adopt e-learning for studying english in chinese higher education context: A structural equation modelling approach. Education and Information Technologies, 1-19. 
Liu, M., \& Liu, C. (2020). The adoption of e-learning beyond MOOCs for higher education. International Journal of Accounting $\mathcal{E}$ Information Management.

Mikhaylov, N.S., \& Fierro, I. (2015). Social capital and global mindset. Journal of International Education in Business.

Nikolopoulou, K., Gialamas, V., \& Lavidas, K. (2021). Habit, hedonic motivation, performance expectancy and technological pedagogical knowledge affect teachers' intention to use mobile internet. Computers and Education Open, 2, 100041.

Park, J., Ahn, J., Thavisay, T., \& Ren, T. (2019). Examining the role of anxiety and social influence in multi-benefits of mobile payment service. Journal of Retailing and Consumer Services, 47, 140-149.

Purbojo, R. (2018). Role of the university lecturer in an online learning environment: an analysis of moodle features utilized in a blended learning strategy. In Educational Technology to Improve Quality and Access on a Global Scale (pp. 227244). Springer, Cham.

Qazi, W., Raza, S.A., \& Khan, K.A. (2020a). The contradiction between self-protection and self-presentation on knowledge sharing behaviour: evidence from higher education students in Pakistan. International Journal of Knowledge and Learning, 13(3), 246-271.

Qazi, W., Qureshi, J.A., Raza, S.A., Khan, K.A. and Qureshi, M.A. (2020b), "Impact of personality traits and university green entrepreneurial support on students' green entrepreneurial intentions: the moderating role of environmental values", Journal of Applied Research in Higher Education, Vol. ahead-of-print No. ahead-of-print. https:/ / doi.org/10.1108/JARHE-05-2020-0130

Raman, A., \& Don, Y. (2013). Preservice teachers' acceptance of learning management software: An application of the UTAUT2 model. International Education Studies, 6(7), 157-164.

Rana, N.P., Dwivedi, Y.K., \& Williams, M.D. (2013). Evaluating alternative theoretical models for examining citizen centric adoption of e-government. Transforming Government: People, Process and Policy.

Raza, S.A., Qazi, W., Umer, B. and Khan, K.A. (2020), "Influence of social networking sites on life satisfaction among university students: a mediating role of social benefit and social overload", Health Education, Vol. 120 No. 2, pp. 141-164. https:// doi.org/10.1108/HE-07-2019-0034

Raza, S. A., Qazi, W., Khan, K. A., \& Salam, J. (2021). Social Isolation and Acceptance of the Learning Management System (LMS) in the time of COVID-19 Pandemic: An Expansion of the UTAUT Model. Journal of Educational Computing Research, 59(2), 183-208.

Raza, S.A. and Khan, K.A. (2021), "Knowledge and innovative factors: how cloud computing improves students' academic performance", Interactive Technology and Smart Education, Vol. ahead-of-print No. ahead-of-print. https://doi.org/ 10.1108/ITSE-04-2020-0047

Ringle, C.M., Wende, S., \& Becker, J.M. (2015). SmartPLS 3.2. 7. SmartPLS GmbH: Bönningstedt, Germany.

Ringle, C.M., Wende, S., \& Will, A. (2005). SmartPLS 2.0 M3 Beta. 
Salloum, S.A., Al-Emran, M., Shaalan, K., \& Tarhini, A. (2019). Factors affecting the E-learning acceptance: A case study from UAE. Education and Information Technologies, 24(1), 509-530.

Shehzadi, S., Nisar, Q.A., Hussain, M.S., Basheer, M.F., Hameed, W.U., \& Chaudhry, N.I. (2020). The role of digital learning toward students' satisfaction and university brand image at educational institutes of Pakistan: a post-effect of COVID-19. Asian Education and Development Studies.

Sidik, D., \& Syafar, F. (2020). Exploring the factors influencing student's intention to use mobile learning in Indonesia higher education. Education and Information Technologies, 25(6), 4781-4796.

Straub, D.W. (1989). Validating instruments in MIS research. MIS quarterly, 147-169.

Šumak, B., \& Šorgo, A. (2016). The acceptance and use of interactive whiteboards among teachers: Differences in UTAUT determinants between pre-and postadopters. Computers in Human Behavior, 64, 602-620.

Šumak, B., Polancic, G., \& Hericko, M. (2010, February). An empirical study of virtual learning environment adoption using UTAUT. In 2010 Second international conference on mobile, hybrid, anonlinene learning (pp. 17-22). IEEE.

Tabachnick, B.G., \& Fidell, L.S. (2007). Multivariate analysis of variance and covariance. Using multivariate statistics, 3, 402-407.

Tandon, U. (2020). Factors influencing adoption of online teaching by school teachers: A study during COVID-19 pandemic. Journal of Public Affairs, e2503.

Tarhini, A., Al-Busaidi, K.A., Mohammed, A.B., \& Maqableh, M. (2017). Factors influencing students' adoption of e-learning: a structural equation modeling approach. Journal of International Education in Business.

Teo, T. (2014). Preservice teachers' satisfaction with e-learning. Social Behavior and Personality: an international journal, 42(1), 3-6.

Teo, T., \& Noyes, J. (2014). Explaining thIntentionon to use technology among preservice teachers: a multi-group analysis of the Unified Theory of Acceptance and Use of Technology. Interactive Learning Environments, 22(1), 51-66.

Uğur, N.G., \& Turan, A.H. (2018). E-learning adoption of academicians: a proposal for an extended model. Behaviour \& Information Technology, 37(4), 393-405.

Vankatesh, V., Morris, M.G., Davis, G., \& Davis, F.D. (2003). User acceptance of information technology: toward a unified view. Mis Quarterly, 27(3), 425-478.

Venkatesh, V., \& Bala, H. (2008). Technology acceptance model 3 and a research agenda on interventions. Decision sciences, 39(2), 273-315.

Venkatesh, V., Thong, J.Y., \& Xu, X. (2012). Consumer acceptance and use of information technology: extending the unified theory of acceptance and use of technology. MIS quarterly, 157-178.

Villesseche, J., Le Bohec, O., Quaireau, C., Nogues, J., Besnard, A. L., Oriez, S., \& Lavandier, K. (2019). Enhancing reading skills through adaptive e-learning. Interactive Technology and Smart Education.

Vinodh, K., \& Mathew, S.K. (2012, December). Web personalization in technology acceptance. In 2012 4th international conference on intelligent human computer interaction (IHCI) (pp. 1-6). IEEE. 
Wong, A., \& Jeganathan, S. (2020). Factors that influence e-learning adoption by international students in Canada. International Journal of Management in Education, 14(5), 453-470.

Welsh, E.T., Wanberg, C.R., Brown, K.G., \& Simmering, M.J. (2003). E-learning: emerging uses, empirical results and future directions. International Journal of Training and Development, 7(4), 245-258.

Yadav, R., Sharma, S.K., \& Tarhini, A. (2016). A multi-analytical approach to understand and predict the mobile commerce adoption. Journal of enterprise information management.

Yadegaridehkordi, E., Nilashi, M., Shuib, L., Nasir, M.H.N.B.M., Asadi, S., Samad, S., \& Awang, N.F. (2020). The impact of big data on firm performance in hotel industry. Electronic Commerce Research and Applications, 40, 100921

Yuan, T., Cheng, J., Zhang, X., Liu, Q., \& Lu, H. (2015). How friends affect user behaviors? An exploration of social relation analysis for recommendation. Knowledge-Based Systems, 88, 70-84.

Zhang, J.H., Zou, L.C., Miao, J.J., Zhang, Y.X., Hwang, G.J., \& Zhu, Y. (2020). An individualized intervention approach to improving university students' learning performance and interactive behaviors in a blended learning environment. Interactive Learning Environments, 28(2), 231-245.

Zhang, Z., Cao, T., Shu, J., \& Liu, H. (2020). Identifying key factors affecting college students' adoption of the e-learning system in mandatory blended learning environments. Interactive Learning Environments, 1-14.

Zhang, S., Zhao, J., \& Tan, W. (2008). Extending TAM for online learning systems: An intrinsic motivation perspective. Tsinghua Science and Technology, 13(3), 312-317.

Zhou, Y., Zhao, J., \& Zhang, J. (2020). Prediction of learners' dropout in E-learning based on the unusual behaviors. Interactive Learning Environments, 1-25.

Zuiderwijk, A., Janssen, M., \& Dwivedi, Y. K. (2015). Acceptance and use predictors of open data technologies: Drawing upon the unified theory of acceptance and use of technology. Government information quarterly, 32(4), 429-440.

Zwain, A.A.A. (2019). Technological innovativeness and information quality as neoteric predictors of users' acceptance of learning management system. Interactive Technology and Smart Education. 
Appendix. Constructs and Instruments.

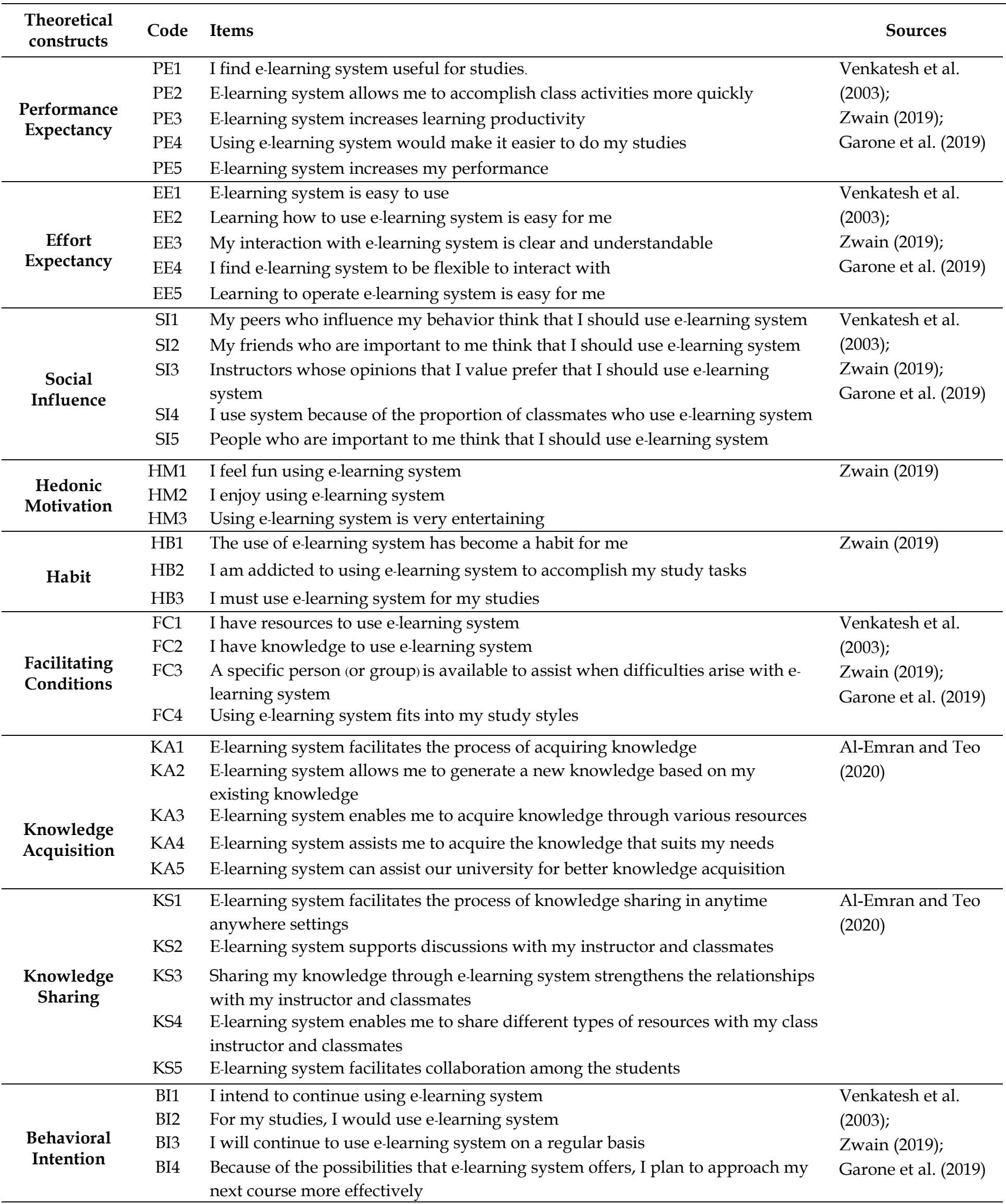

